
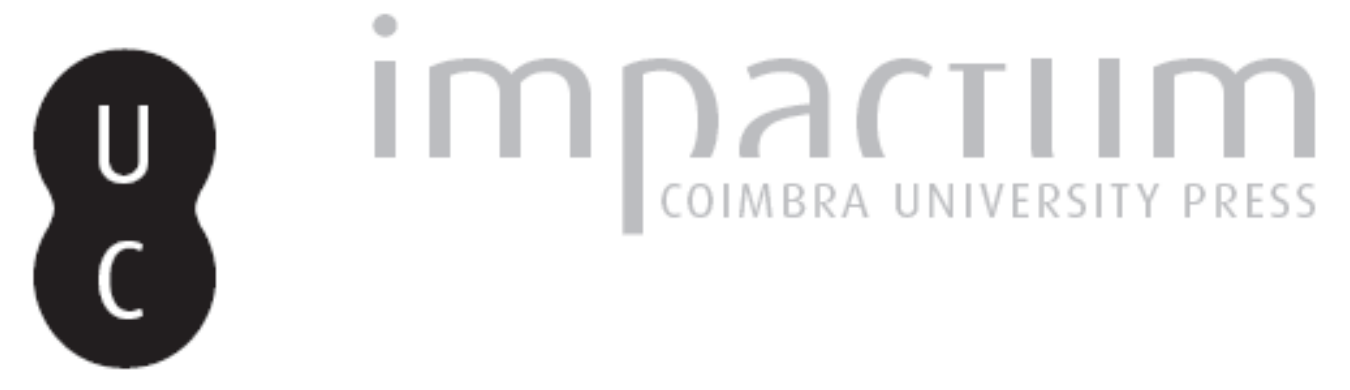

\title{
A Babilónia no destino de Alexandre
}

\section{Autor(es): $\quad$ Caramelo, Francisco}

Publicado por: Centro de História da Universidade de Lisboa

URL persistente:

URI:http://hdl.handle.net/10316.2/23735

DOI:

DOI:http://dx.doi.org/10.14195/0871-9527_20_17

Accessed : $\quad$ 26-Apr-2023 14:49:20

A navegação consulta e descarregamento dos títulos inseridos nas Bibliotecas Digitais UC Digitalis, UC Pombalina e UC Impactum, pressupõem a aceitação plena e sem reservas dos Termos e Condições de Uso destas Bibliotecas Digitais, disponíveis em https://digitalis.uc.pt/pt-pt/termos.

Conforme exposto nos referidos Termos e Condições de Uso, o descarregamento de títulos de acesso restrito requer uma licença válida de autorização devendo o utilizador aceder ao(s) documento(s) a partir de um endereço de IP da instituição detentora da supramencionada licença.

Ao utilizador é apenas permitido o descarregamento para uso pessoal, pelo que o emprego do(s) título(s) descarregado(s) para outro fim, designadamente comercial, carece de autorização do respetivo autor ou editor da obra.

Na medida em que todas as obras da UC Digitalis se encontram protegidas pelo Código do Direito de Autor e Direitos Conexos e demais legislação aplicável, toda a cópia, parcial ou total, deste documento, nos casos em que é legalmente admitida, deverá conter ou fazer-se acompanhar por este aviso.

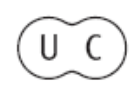




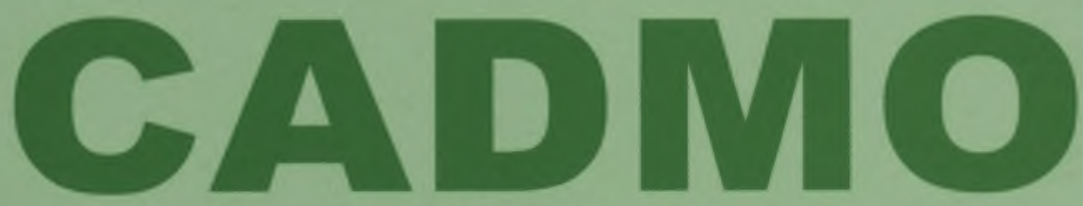

Revista de História Antiga

\author{
Centro de História \\ da Universidade de Lisboa
}

\title{
20
}

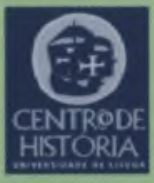

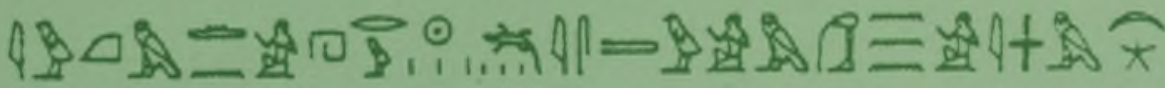

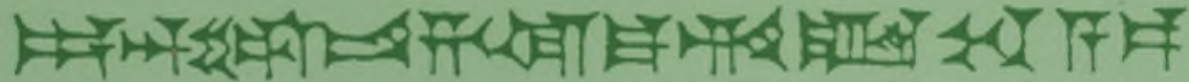

MHNIN AEI $\Delta$ E $\Theta E A ~ \Pi H \Lambda H I A \triangle E \Omega$ 


\title{
A BABILÓNIA NO DESTINO DE ALEXANDRE
}

\author{
FRANCISCO CARAMELO
}

Universidade Nova de Lisboa

F.Caramelo@netcabo.pt

\section{Resumo}

A Babilónia era, ainda no tempo de Alexandre, uma grande metrópole, inspirando o fascínio do mundo de então. Os relatos que reportam a relação de Alexandre com a Babilónia concentram-se sobretudo nos episódios da conquista da cidade e da morte do rei. Paralelamente ao carácter sinóptico patente nas narrativas que aludem a esses dois episódios, observa-se também que esses relatos são claramente condicionados por estereótipos literários e por formas textuais e intertextuais que algo terão ficado a dever à recepção de topoi babilónicos.

Palavras-chave: Babilónia; Alexandre; Caldeus; Adivinhação.

\begin{abstract}
Babylon was, still in the time of Alexander, a great metropolis, inspiring the world. The stories that report the relation of Alexander with Babylon focus mainly in the episodes of the conquest of the city and the death of the king. Beyond the synoptic nature of those narratives, we notice also that these stories are clearly conditioned by literary stereotypes and textual and intertextual forms which are probably connected with the reception of Babylonian topoi.
\end{abstract}

Key-words: Babylon; Alexander; Chaldeans; Divination. 
Alexandre está indubitavelmente ligado à Babilónia. É à grande metrópole que o rei macedónico regressa após o seu longo périplo por terras asiáticas e é na urbe mesopotâmica que vive os seus últimos dias. As narrativas literárias que chegaram até nós, inspiradas em fontes primárias entretanto desaparecidas e porventura numa tradição oral que urde e desenvolve a heroicização do monarca, descrevem os episódios desses derradeiros dias, envoltos num mistério que entretece a hagiografia de Alexandre.

O regresso do rei e do seu exército à Babilónia reflecte o lugar central que esta ocupava no espaço político do império, confirmando a importância que a cidade já tinha durante a hegemonia persa aqueménida e no contexto da visão policêntrica(1) que os Persas tinham do seu império. As narrativas biográficas relatam, em versões sinópticas, esta última fase da vida de Alexandre, conferindo-lhe um carácter premonitório e eivado de superstições que anunciavam a morte do rei.

Plutarco, no relato biográfico que dedica a Alexandre, refere que Nearco, quando reencontrou o rei, o alertou para o facto de os caldeus $^{(2)}$ o terem prevenido acerca do perigo que atravessaria se se aproximasse da Babilónia ${ }^{(3)}$. Apesar da advertência, Alexandre terá desvalorizado a recomendação. No entanto, os avisos não se ficaram por aí. Quando se acercou da cidade e se encontrava já junto às muralhas, o rei testemunhou pessoalmente um augúrio. Observou no céu os corvos que voavam de forma estranha, atacando-se uns aos outros, vindo algumas das aves morrer a seus pés ${ }^{(4)}$.

Putarco narra ainda uma terceira ocorrência, a qual é coerente com as anteriores. Alexandre terá sido informado de que Apolodoro, o comandante da Babilónia, indagou acerca do destino do rei através de um sacrifício, procedendo a uma consulta por hepatoscopia. O rei procurou confirmar esta informação, chamando Pitágoras, o adivinho, que corroborou o facto, acrescentando que o fígado da vítima não apresentava lóbulo. Esta terceira ocorrência foi levada a sério por Alexandre, interpretando o facto como um mau prenúncio. Arrependeu-se de não ter valorizado as palavras de Nearco e decidiu passar a maior parte do seu tempo fora de Babilónia ou navegando no Eufrates ${ }^{(5)}$.

Diodoro faz-se eco também do episódio que relata o encontro de Alexandre com os caldeus, esclarecendo que estes eram especialistas em astrologia. Não abordaram directamente o rei, tendo sido Nearco a informar Alexandre. O autor é mais explícito do que Plutarco quanto ao prenúncio da morte do rei. Os caldeus procuram demovê-lo da sua intenção de entrar na Babilónia, asseverando-lhe que isso the seria 
fatal. Diodoro acrescenta, no entanto, um dado novo: Alexandre poderia evitar o destino anunciado se tornasse a erigir a tumba de Belo, a qual havia sido destruída pelos Persas, e se decidisse não entrar na cidade $^{(6)}$. O rei levou a sério os presságios, sobretudo porque era conhecida a reputação destes adivinhos. Segundo Diodoro, a notícia perturbou-o profundamente. Decidiu não entrar na cidade, tendo-se instalado a certa distância ${ }^{(7)}$.

Diodoro, neste seu relato, reflecte, a propósito da chegada dos Greco-Macedónios à Babilónia, de forma assaz interessante, a contradição entre a perspectiva mística e metafísica, que correspondia às práticas da adivinhação em que os Babilónios eram hábeis, e a lógica filosófica que impelia os Gregos e, entre eles, Anaxarco, um filósofo, a persuadir Alexandre a entrar na metrópole. Alexandre cedeu aos argumentos filosóficos, acabando finalmente por entrar na cidade, sendo recebido efusivamente pelos locais ${ }^{(8)}$.

Arriano, na Anábase, retoma o tema da entrada de Alexandre na Babilónia. Informa que durante a sua marcha em direcção à metrópole uns caldeus vieram ao seu encontro e que o quiseram dissuadir de entrar na cidade. Acrescenta um aspecto novo em relação às versões anteriores quando esclarece que a intervenção dos adivinhos tem origem num oráculo de Bê((9), que comunicou que a entrada de Alexandre na cidade Ihe seria fatal(10). Desviar a rota envolvia dificuldades, 0 que também não terá facilitado a mudança de atitude de Alexandre. Arriano interpreta esta atitude de uma forma que traduz bem a sua visão fatalista sobre os acontecimentos, declarando que a divindade determinava as acções do rei e o levaria exactamente ao lugar onde ele estava destinado a morrer ${ }^{(11)}$.

Arriano regista nesta parte do seu texto a contradição entre duas posições. De um lado, está aparentemente o próprio autor ao reflectir uma visão fatalista acerca do destino do rei; do outro, encontra-se o próprio Alexandre, que desconfia dos caldeus e vê a sua intervenção não como o efeito de uma profecia ou de um presságio mas antes como o resultado de interesses concretos e materiais ${ }^{(12)}$.

O autor explica que o templo de Bêl se localizava no centro da cidade e que era enorme, construído em adobe e betume. Havia sido destruído por Xerxes, assim como muitos outros santuários da Babilónia, aquando do seu regresso da campanha na Grécia. Alexandre manifestara a intenção de o reconstruir, interpretando, dessa forma, um dos traços mais significativos e assumindo um dos estereótipos comuns do rei mesopotâmico e da sua piedade. Como os trabalhos pouco 
haviam progredido desde a sua primeira passagem pela cidade, diz Arriano que Alexandre tencionava entregar ao seu próprio exército a tarefa da reconstrução. Aí residiria, segundo Alexandre, a razão da atitude dos caldeus, explicada por Arriano. Os proventos que os Assírios outrora doavam ao templo, essencialmente destinados à realização de sacrifícios e de outras cerimónias religiosas, eram agora distribuídos entre os caldeus. Alexandre suspeitava que os caldeus não teriam, assim, qualquer interesse em concluir as obras de reconstrução do templo e que seria essa a verdadeira razão que explicava a sua oposição à entrada do rei na cidade ${ }^{(13)}$.

Arriano evoca ainda Aristóbulo, narrando um outro episódio que se prende com este topos literário da entrada de Alexandre na Babilónia, a que os vários biógrafos aludem de forma mais ou menos circunstanciada. Segundo o autor, o rei ter-se-á deixado convencer, aceitando contornar a cidade. Acontece que as dificuldades do terreno e, em particular, as suas características pantanosas forçaram-no a alterar o rumo, desobedecendo, desta forma, ao deus ${ }^{(14)}$. A narrativa de Arriano encontra-se, por conseguinte, dominada por esta oposição entre a visão fatalista do próprio autor, a qual explica o destino de Alexandre e a sua morte como o resultado do presságio e do acto de desobediência à vontade divina, e a perspectiva mais materialista do rei que desconfia da atitude dos caldeus e que a interpreta como o produto dos seus próprios interesses.

Os relatos de Plutarco e as correspondentes versões apresentadas por Diodoro e por Arriano têm em comum a identificação da Babilónia como terra non grata. Todos os presságios apontavam para uma fatalidade caso Alexandre atravessasse as muralhas e permanecesse na cidade. O paradoxo é evidente. Por um lado, a Babilónia constitui o lugar do doce regresso, do prometido descanso após a longa errância por terras remotas; por outro, os augúrios sobre Alexandre prenunciam-Ihe a desdita e quiçá a própria morte.

Plutarco regista outros presságios que atestam o prenúncio da tragédia. Nestes casos, trata-se de situações insólitas e cujo carácter inusitado é interpretado como sinal, isto é, como presságio. Numa primeira ocorrência, um burro, acercando-se de um leão que pertencia a Alexandre, escoiceou-o até à morte ${ }^{(15)}$. Outra ocorrência regista o facto de o rei ter despido as suas roupas com a finalidade de se exercitar com os seus companheiros. Após o exercício, encontraram um homem sentado no trono, em silêncio, envergando o diadema e a indumentária real. Foi interrogado e forçado a revelar a sua identidade. Confessou que havia 
estado preso durante muito tempo e que Serápis o libertara, ordenando-l the que agisse desta forma ${ }^{(16)}$. Alexandre, ao tomar conhecimento desta situação e aconselhado pelos adivinhos, mandou matar o homem ${ }^{(17)}$.

A disposição de Alexandre mudou radicalmente a partir destes presságios. O rei tornou-se taciturno, desconfiando de todos, mesmo

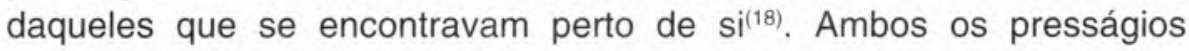
estão intimamente associados ao destino de Alexandre. O leão era quase universalmente identificado com a realeza. $\mathrm{Na}$ Mesopotâmia, a iconografia representa abundantemente o animal e é frequente o recurso a uma imagética, designadamente nos baixos-relevos neo-assírios, em que o leão é figurado em cenas de caça onde o monarca ocupa um papel de relevo.

Diodoro apresenta um relato sobre o episódio em que um homem assume a identidade do rei muito similar ao que Plutarco descreve. Conta o autor que Alexandre estava a ser ungido com azeite e que o fato e o seu diadema estavam depositados sobre um cadeirão. Um dos prisioneiros, libertando-se das cordas que o prendiam, e sem que os guardas dessem conta, atravessou a porta do palácio sem que ninguém o impedisse, acercou-se da cadeira, vestiu o fato real e colocou o diadema, permanecendo ali, imóvel.

Ao saber do episódio, Alexandre mostrou-se inquieto e preocupado. O homem foi interrogado mas não esclareceu as suas intenções, o que levou o rei a consultar os adivinhos. O veredicto conduziu o homem à morte, esperando-se que as desgraças anunciadas fossem transferidas para o estranho intruso, anulando-se assim qualquer efeito sobre Alexandre. A sua roupa foi oferecida em sacrifício aos deuses apotropaicos, procurando assim afastar o mal que o ameaçava ${ }^{(19)}$.

A versão de Diodoro, com algumas diferenças, parece identificar-se claramente com a narrativa de Plutarco. Também Arriano, evocando Aristóbulo, narra o mesmo episódio. Conta que Alexandre, com sede, terá deixado a cadeira real. Um homem, segundo alguns, um condenado, vendo o trono desocupado, apressou-se a tomar o lugar do rei. Repete-se o interrogatório ao homem, o qual mais uma vez não produz quaisquer efeitos, uma vez que aquele não esclarece a razão e a motivação do seu acto(20).

Os três biógrafos relatam um episódio de contornos muito semeIhantes e aparentemente desconhecem o seu significado no contexto cultural e religioso da Mesopotâmia. As versões podem variar em alguns aspectos de pormenor mas coincidem no essencial. O episódio, protagonizado por um homem de baixa ou de obscura condição, que 
não esclarece ou não sabe a razão da sua atitude, ocorre sem que se descortine o que o origina. O homem, movido por uma vontade divina, é impelido a agir, como que cumprindo um plano superior, o que é compreendido como um presságio da desgraça anunciada.

Esta percepção do episódio, mais ou menos comum aos três autores, deixa escapar o significado cultural e religioso que ele teria no mundo mesopotâmico. Os Mesopotâmios acreditavam que um mau presságio para o soberano poderia ser ultrapassado se entronizassem temporariamente um rei substituto, remetendo o verdadeiro rei, durante cem dias, para uma existência sombria que o protegeria a ele e ao país. Entretanto, nem sequer o podiam interpelar como monarca, fazendo sentar no trono um rei e uma rainha substitutos que atrairiam sobre si todo o mal que havia sido vaticinado.

Após os cem dias, período durante o qual o verdadeiro monarca, anulando a sua identidade, estivera escondido ou tendo uma existência discreta e o seu substituto se sentara no trono, tornando-se o potencial alvo de todos os males e de todos os presságios, este último é conduzido à morte, confirmando-se assim o destino anunciado, ainda que transferido para outra pessoa. Na nossa opinião, o episódio descrito nas três versões constitui a ressonância dessa prática mágico-religiosa, bem como dessa concepção de destino que os autores gregos interpretaram de forma impressionista.

Diodoro narra um outro episódio que também lembra esta concepção da substituição. Trata-se de outro presságio, interpretado como mais um sinal sobre a realeza. Alexandre decidira passear de barco e, afastando-se dos seus companheiros, perdeu-se. O seu barco errou solitário durante dias, levando o rei a temer pela própria vida. Navegando por um estreito canal, o seu diadema acabou por ficar preso nos ramos de uma árvore e caiu à água. Um dos remadores lançou-se à água e, na sua preocupação de não perder o diadema, colocou-o sobre a própria cabeça, nadando, em seguida, até à barca real. Após três dias de errância, encontraram o caminho de regresso(21).

Arriano, com diferenças de pormenor, narra a mesma história. Alexandre navegava nos pântanos adjacentes à Babilónia e perdeu-se. Um vento forte levou-lhe o diadema, ficando preso num arbusto, o qual crescia junto a um dos túmulos dos antigos reis. Tal como na narrativa de Diodoro, Arriano conta que alguém nadou e recuperou o diadema, colocando-o na sua própria cabeça. Acrescenta que compensou o homem com um talento, no entanto, em seguida, aconselhado pelos adivinhos, mandou que Ihe cortassem a cabeça(22). 
Este episódio, descrito por Arriano e por Diodoro, insinua também a ideia de substituição. O diadema de Alexandre e o túmulo real constituem signos cujo significado remete obviamente para a ideia de realeza. Ora, o facto de o diadema cair da cabeça do monarca, que era o seu lugar natural, e ir parar precisamente junto ao túmulo de um antigo rei foi compreendido como um mau presságio, associando-se o destino de Alexandre a uma morte anunciada.

A percepção que os três autores têm desta última fase da vida de Alexandre, intimamente ligada à Babilónia e a um ambiente cultural e religioso caracterizado por estas crenças e práticas dominadas pela adivinhação e pela magia, reflecte a dialéctica entre uma perspectiva filosófica e material da vida e do destino e uma visão metafísica e mística do mundo. O próprio Alexandre, tal como é descrito por estes autores, oscila entre uma e outra. Ora escuta os filósofos e rejeita os conselhos dos caldeus, ora se arrepende de ter dado ouvidos aos Gregos e reconhece a sabedoria e o prestígio dos adivinhos, deixando que o seu comportamento e as suas decisões sejam condicionados por eles e pelos seus alvitres.

Segundo Plutarco, Alexandre tornou-se muito susceptível e sensível aos presságios, preocupado com todos os aspectos inusitados do quotidiano, onde imediatamente via um significado sobrenatural. Mostrava-se apreensivo e preocupado, sombrio, fazendo-se rodear de adi$v^{\text {vinhos }}{ }^{(23)}$. Este comportamento devia-se, na opinião de Plutarco, à insegurança que Alexandre sentia, desconfiando de tudo e de todos os que o rodeavam, mesmo dos seus amigos ${ }^{(24)}$.

Plutarco transmite-nos o retrato de um Alexandre que se foi tornando taciturno e místico. Diodoro contribui igualmente para este retrato do rei. Segundo o autor, Alexandre maldizia os filósofos e arrependia-se de não haver seguido os avisos dos caldeus quando estes o procuraram dissuadir de entrar na Babilónia ${ }^{(25)}$. Não deixa de ser interessante, esta dialéctica entre o paradigma do filósofo e o paradigma do adivinho na indagação da verdade e do destino.

Nestes relatos, é por vezes difícil destrinçar entre a verosimilhança histórica das narrativas, isto é, a sua historicidade, e a visão secundária ${ }^{(26)}$, literária e anacrónica dos autores. A lógica da narrativa pressupõe um enredo literário que prepara o leitor para a iminência da morte de Alexandre. Essa linha narrativa, que nos conduz até esse clímax, a morte do rei, é pontuada por diversos episódios em que Alexandre, entre filósofos e adivinhos, se vai progressivamente tornando mais obscuro e nocturno(27). 


\section{Notas}

(1) Sobre esta visão policêntrica, cf. PIERRE BRIANT, Histoire de l'Empire Perse, Paris, Fayard, 1996.

(2) Os caldeus são mencionados nestas narrativas não como um etnónimo mas antes como uma referência aos adivinhos e sacerdotes babilónicos.

(3) Plut. Alex. 73, 1. Também Arriano, na Anábase, alude ao mesmo episódio: Arriano, Anáb. vii, 16,5. Segundo o autor, teriam sido os próprios caldeus a avisar Alexandre de que não deveria entrar em Babilónia.

(4) Plut. Alex. 73, 1.

(5) Plut. Alex. 73, 2.

(6) Diodoro refere-se, provavelmente, à zigurate da Babilónia.

(7) Diod. Biblioteca Histórica 17, 112.

(8) Diod. Biblioteca Histórica 17, 112.

(9) Trata-se do deus Marduk, a divindade principal do panteão babilónico.

(10) Arriano, Anáb. vii, 16, 5.

(11) Arriano, Anáb. vii, 16, 7.

(12) Arriano, Anáb. vii, 17, 1.

(13) Arriano, Anáb. vii, 17, 2-4.

(14) Arriano, Anáb. vii, 17, 5-6.

(15) Plut. Alex. 73, 3.

(16) Plut. Alex. 73, 3-4.

(17) Plut. Alex. 74, 1.

(18) Plut. Alex. 74, 1.

(19) Diod. Biblioteca Histórica 17, 116, 2-4.

(20) Arriano, Anáb. vii, 24, 2-3.

(21) Diod. Biblioteca Histórica 17, 116, 5-7.

(22) Arriano, Anáb. vii, 22, 1-4.

(23) Plut. Alex. 75, 1.

(24) Plut. Alex. 74, 1.

(25) Diod. Biblioteca Histórica 17, 116, 4.

(26) Estes relatos não são, como sabemos, contemporâneos de Alexandre. A lógica sinóptica das narrativas reflecte a preexistência de fontes anteriores que todos terão seguido.

(27) Este texto constitui a segunda parte e a sequência da comunicação que publicámos nas actas do VI Congresso de Estudos Clássicos, o qual teve lugar na Faculdade de Ciências Sociais e Humanas da Universidade Nova de Lisboa, em 2006. 